لا J ك ك للقلسفة واللسانيات والعلوم الاجتماعية العدد الثاني السنة الثانية

\title{
الميتافيزيقا عند وايتهيد
}

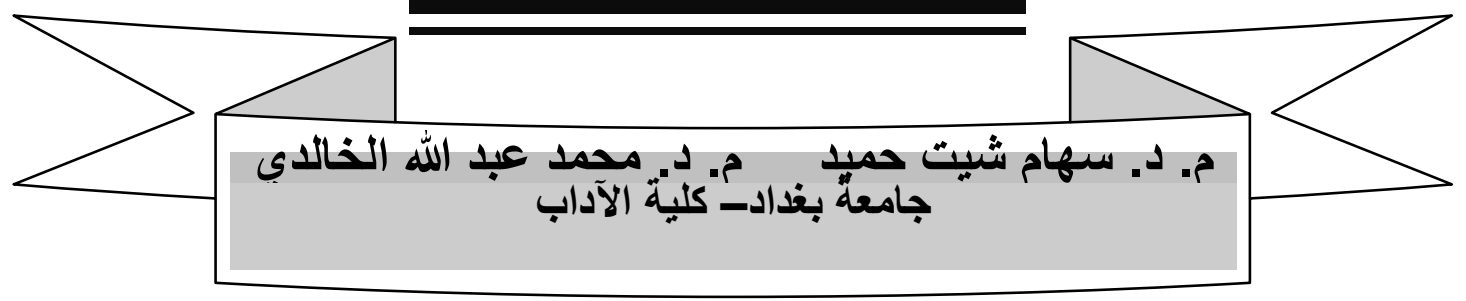

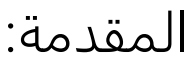

الفرد نورث وايتهيد فيلسوف انكليزي ولد في عام 1861م، دخل جامعة كامبردج وتخرج

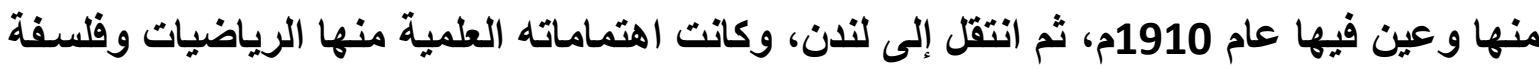
العلم، ثم الميتافيزيقيا، له مؤلقات مهمة في تاريخ الفكر العلمي والفلسفي، أهمها1:

$$
\text { ـ ـ ـ ـ الدلم والعالم العديث نثر عام } 1925 .
$$

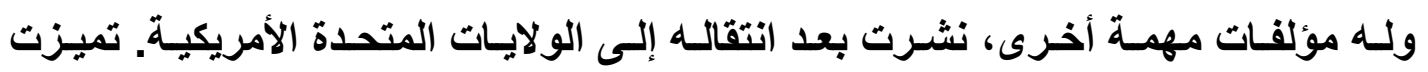

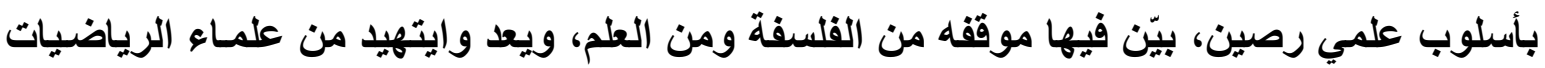

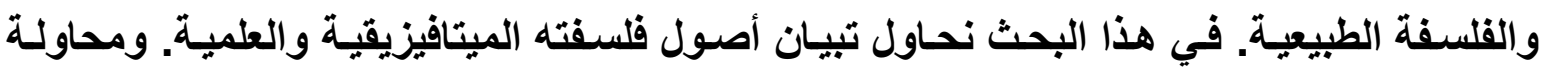

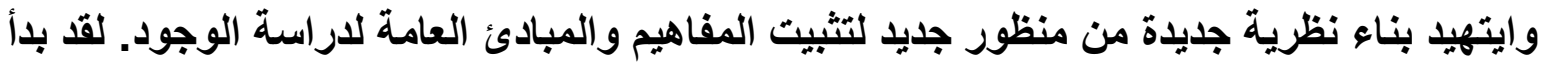

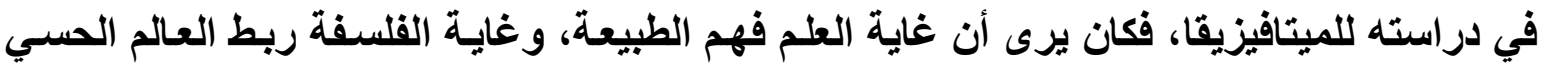

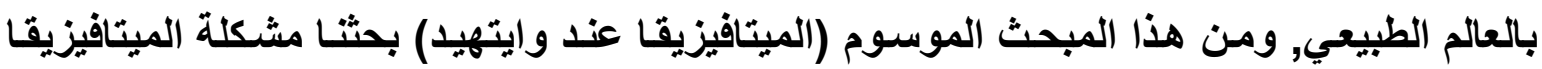

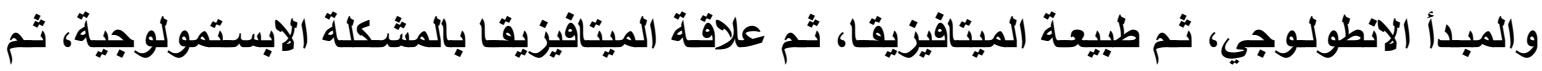

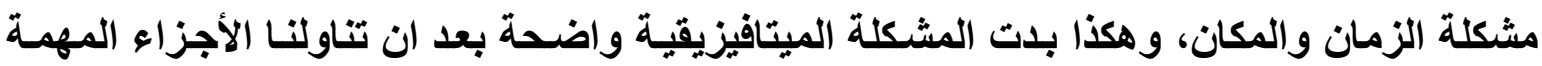
منها ومعرفة موقف الفيلسوف منها وهي كالآتي:

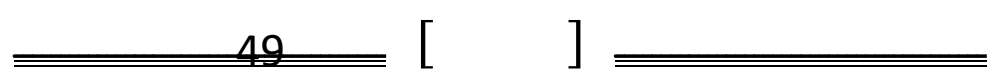


ل

1. موقف وايتهيا من دراسة الوجود والمبدأ الانظولوجي: كان وايتهيد متفقاً مع أرسطو فيما يتعلق بأسـاس المشكلة الميتافيزيقية فقد ذهب الاثنان الى أن المشكلة الميتافيزيقية تتركز في البحث عن فئ

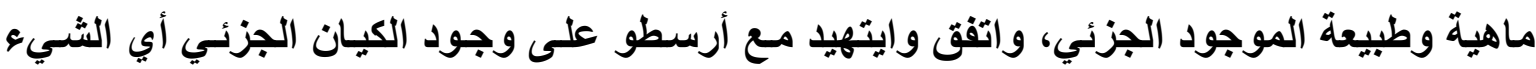

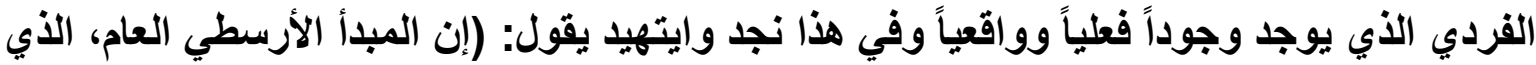
سلمنا به، يقرر أنه بمعزل عن الأشياء الفعلية لا يوجد شيء ، لايوجد شيء واقعي، أو شيء لـه له (2) أدنى تأثير).

إن وايتهيذ يستعمل كلمة فعلي Actual لكي يصف بها الأثباء الجزئية لاسيما في كتابهـ

(التطور وعالم الواقع). إن هذا المصطلح يعني الوجود بكل ما تحمله الكلمة أي بمعنى الوجود الذي

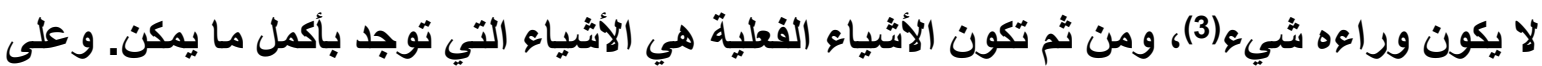
هذا فهذه الأثياء هي الموجودة بحق، إما كلمة كيان (Entity) فهي مرادفة تماماً في اللغة اللاتينية لكلمة Thing، وفكرة الكيان فكرة مهمة جداً، ويرى وايتهيد انه يمكن التمبيز بين تلك الكيانات عن هن طريق استعمال مصطلح (فعلي Actual) إذ تميز كلمـة فعلي بين الكيانـات المستقلة والكيانـات ذات الوجود الكامل عن الكيانات الأخرى التي هي ليست كذلك, فالفعلي من الكيانات يشير إلى وجود آخر

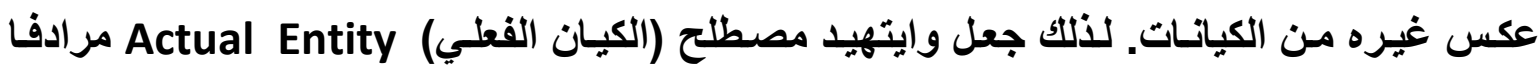
للمصطلح الارسطي Ovoiu وهذا المصطلح الذي ذكره أرسطو في فلسفته الميتافيزيقا الذي يمكن أن يشير إلى ذلك الكيان الجزئس أو إلى الثيء الفردي الذي يوجد وجود فعلي وواقعي لقد أدرك وايتهيد أن هذه الحقيقـة وهي: أن الأشياء الموجودة وجودا تامـا تمثل الاهتمـام الرئيسي للبحثي الميتافيزيقي.

كان تأثر وايتهيد بأرسطو واضحاً جدلاًٍ في موضوع (الكيانـات) وعدّ ذلك المفهوم مفهومـاً انطولوجياً وأساسياً في فلسفته, ولمفهوم الكيانات الفعلية أثز أساس في المشكلات الميتافيزيقية. أن المبدأ الانطولوجي يعني فلسفياً علماً يقوم بلراسة الوجود، وهذه الدراسة تختلف في جوهرهـا عن الانثرويولوجيا، التي تهتم بعلم الإنسان، فالانطولوجيا تدرس الضوء الذي يكشف عن التوجي الموجودات،

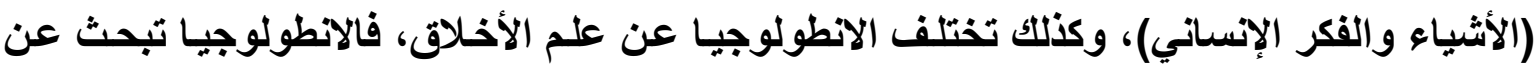
الحقيقة، وعن المطلق، وهذان المفهومـان هما جوهر الدراسـة الميتافيزيقيـة (فالحقيقة والمطلق الإنق غاية من غايات القلسفة).

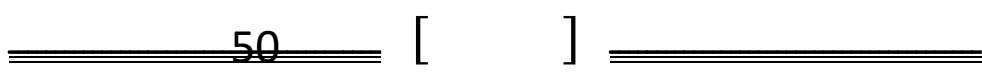


ل

ويعرف الدكتور محمود رجب الانطولوجيا بقوله: (أنها البحث في معنى الوجود بما هو حقيقة

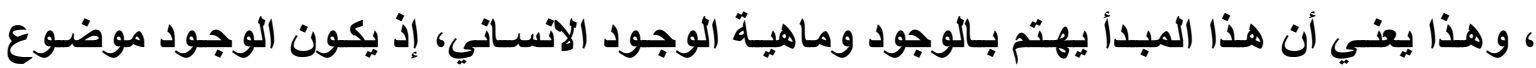
اهتمامـه الرئيس، على أن يكون هذا الوجود وجود الكيانـات الفعليةActual Entities التي وحدها

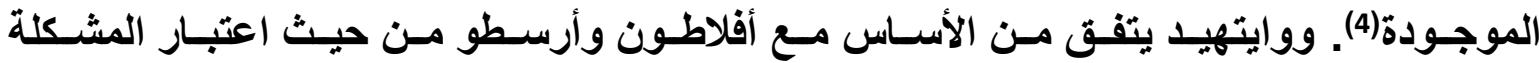
الميتافيزيقية الرئيسية هي: مشكلة الطبيعة القصوى للأثباء، وهي مشكلة الوجود. ان هذا الموقف

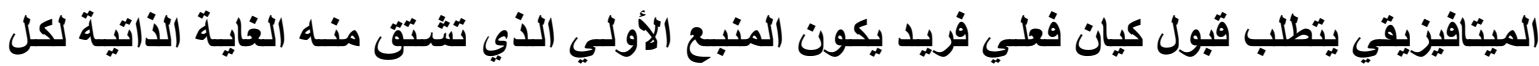
كيان فعلي. وأشار وايتهيا إلى أن هذه المشكلة هي نفسها التي واجهها أرسطو في المسألة نفسـها وحلهـا بالطريقة نفسـها(6). كاتـت هذه المشكلة القلسفية الأولى تحت دائرة البحث القلسفي عند الفلاسفة السـابقين ويشير ويوضـح بذلك وايتهيـ موقفه مـ فكرة أرسطو: (حينمـا بحث المسـألة

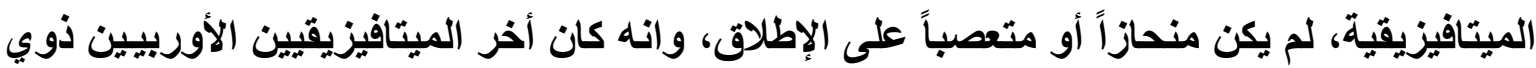
الأنصـاف، وبعـد أرســو فـان الاهتمامسات الأخلاقيـة والاينيـة بــأت فـي التـأثير مـن التتــائج

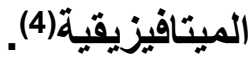

2. مـن المشكلات الأساسية التي اهتم بها وايتهيد في دراسته لمفهومين أساسيين مـن نظرتهـ الميتافيزيقية التي حـاول فيهـا أن يظهر جاتب دراسته مـن فلسـفة العلم والقلسفة العلميـة وهمـا (الصيرورة الطبيعية والديمومة) عن هذا الموضوع يرى دـ ياسين خليل (ان الفريد نورث وايتهيد يضع فلسفة شاملة للكون أسساسها الصيرورة الطبيعة والايمومـة (Process and Reality). وقد اتخذ من حقائق الفيزيـاء والبيولوجيا مسادة لقلسفته في الوجود والمعرفة)(5). ومن خلال دراسته للميتافيزيقيا حاول وايتهيذ فيلسوفا وعالم رياضبات وعالم منطق الافادة من نتائج العلوم الفيزيائية والطبيعة و إخضاع هذه النتائج داخل إطار فلسفي محدد يبين صلات النتائج والاستتناجات القلسفية المترتبة عليها.

فاتصب الثتمامسه في دراسـة مشكلة طبيعة الميتافيزيقيا، ويـرى الدكتور علي عبد المعطي محمد في كتابه (الفرد نورث وايتهيد، فلسفته وميتافيزيقياه) أن: (الميتافيزيقيا عند وايتهيد تمثل جاتباً يمثل جوهر فلسفة الميتافيزيقية ومن هذا كله نفهم ان وايتهيذ يستخدم مصطلح القلسفة التي تلرس الوجود على جهة الشمول والإطلاق، وعلى نحو ما يمكن ان يكون، بـل من الواجب عليهـا، أن ترتفع إلى ما هو أعلى من العالم الطبيعي المحسوس فالقلسفة مبحث يقسم أقسـاماً فرعيـة: مثنل فئل الميتافيزيقيا، والايستمولوجيا والكوزمولوجيا، والأخلاق والجمال...)(6)، فالقلسفة في رأي وايتهيد

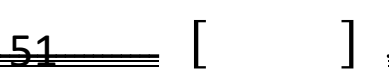


ل

والميتافيزيقيا هي العلم الكلي، وبهذا ينقلـا وايتهيد إلى محاولة جديدة من منظور جديد بسبب المفـاهيم مثنل الكينونـة، الحقيقة، الكون، ويسـى وايتهيد هذه المفــاهيم أنها (المناسبـات الفعليـة) ويعرفها أنها (الأثياء التهائية والواقعية التي يتكون منهـا العالم)(7)، تم يطلق عليها مفهوم آخر فئر

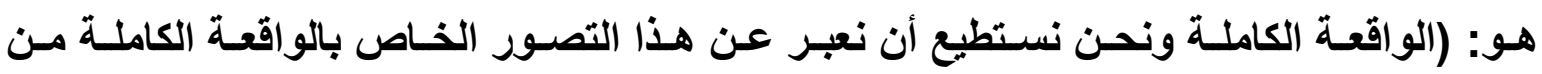

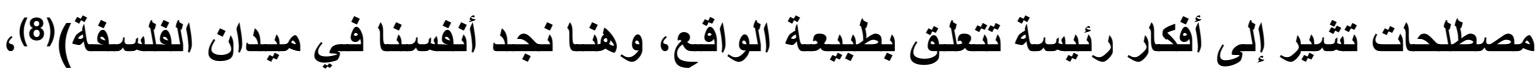
وهنـا يعرف وايتهيـ الميتافيزيقيا أولاً ويقول: (إن القلسفة التأمليـة تحساول تشكيل نسـق مترابط ومنطقي وضروري من الأفكار العامـة، في مصطلحات يمكن عن طريقها تفسير كل عنصر من فن فئنسئ

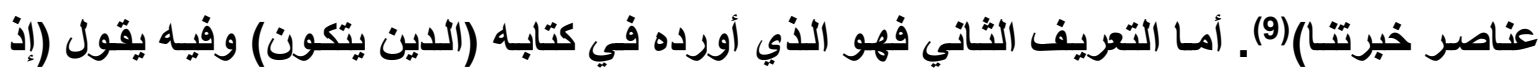
أعني بالميتافيزيقيا العلم الأي يبحث عن اكتثاف الأفكار العامة المناسبة أساساً والتي لاعني عنها بالنسبة إلى تحليل كل شيء يحدث)(10).

ويمكن بعد هذا أن يعد أهم ما يميز الفكر الميتافيزيقي كون الميتافيزيقيا تعمل على استحداث

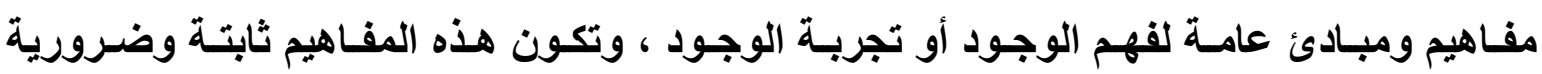

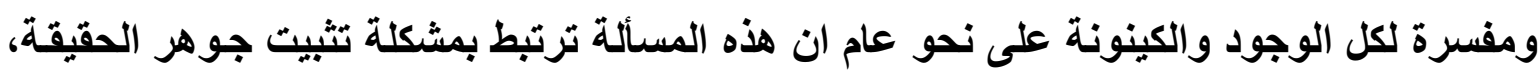

وأما بسبب كونها عامة فنلك كي تكون صالحة لتفسير كل عنصر من عناصر تجربتنا.

ويشترط أيضاً أن يكون النظام ميتافيزيقياً متماسكاً ومنطقياً وممكن التطبيق، ويعني بالتماسك أن تكون القضايا مترابطة ترابطاً عضوياً ومكملة أحداها للأخرى، بحيث لا يكون لها معنى بمعزل

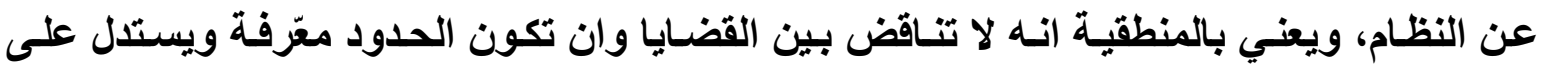
النتائج وحسب قواعد الاستدلال الصحيح. وهذا يعني (ان الميتافيزيقيا تتطلب فهم طبيعة الكيـان

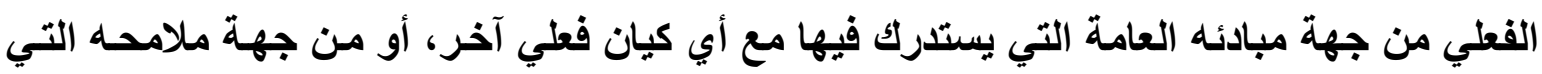
تكون عامة بين كافة الكيانات الفعلية أو تحدد ما تكون عليه أو تبين ماهيتها)(11). إذ أن مـا يحتاج إليه الفكر هو اللعب الحر للخيال الأي تتحكم فيه ضرورات التماسك والمنطق.

وتمثل ميتافيزيقيا وايتهيد أهم وانضج انتقال نقل المعرفة العلمية والمباحث الابستمولوجية إلى المباحث الميتافيزيقية، وعلى الرغم من ان باية فلسفة وايتهيذ تمثل فلسفة الرياضيات إلا انهـ اتجه للاهتمام بمشكلات المعرفة الميتافيزيقية بصورة خاصة للقيام بمعادلة جديدة ومخلصـة لإعـادة المكانة إلى الميتافيزيقا وإنقاذ ما يمكن إنقاذه وبناء الميتافيزيقا على أسس علمية سليمة، والواقع أن الميتافيزيقا عند وايتهيد تحاول ان تبني مذهباً أو نظامـاً يضم الأفكار العامـة، فمثل هذه الأفكار

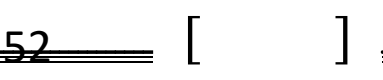


ل

تمكن من تفسير كل عناصر تجربتنا، بحيث تكون هذه الأفكار مترابطة أو متعلقة بعضها ببعض فـ

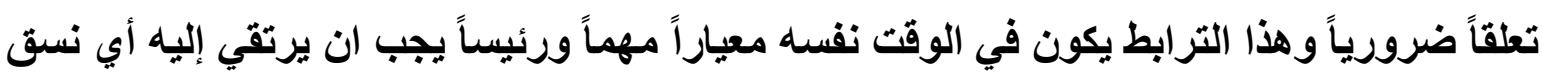

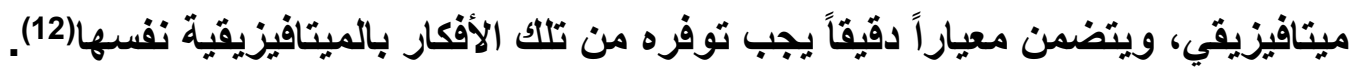
فالميتافيزيقيا بحث منظم عن أسس ومبادئ الكون أو ماهيته وهذا البحث يكوّن نظامـاً مـن

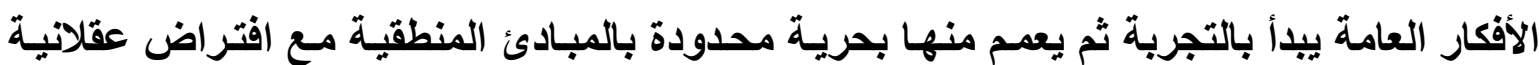

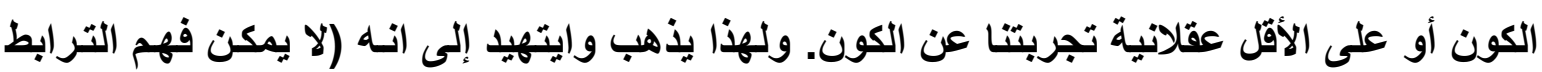
فهماً أعمق وإدراك أهميته القصوى بالنسبة لإقامـة الأنسـاق، والتفهم العقلى الكامل لـه، إذا نظرنـا فيمـا يتـاقض معـه، اعني إذا نظرنـا في الـلا ترابط، إن الـلا ترابط يعني عند وايتهيد ذلك الفصل التعسفي الأي يشير إلى أن المبادئ أو الأفكار لا تحتوي أو لا تملك أية علاقات ترابط وفقها، ومن

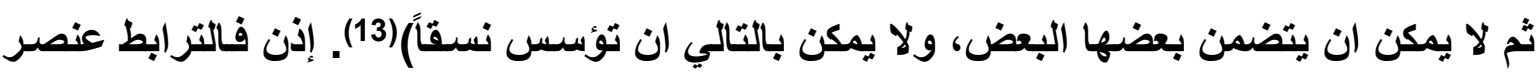

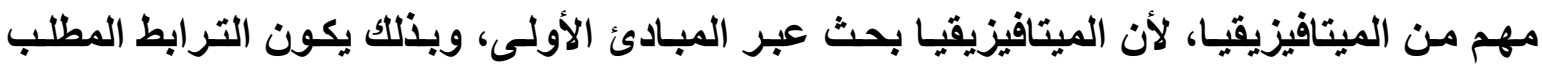
الأساس لبناء مذهب ميتافيزيقي متكامل وهذا ما يقره وايتهيد بوضوح، إذ يقول: (إن الترابط يمثل أعظم واكبر مطلب عقلي سليم)(14)، أي بـالتفكير العقلي السليم يمكنتا الوصـول إلى ترابط الأفكار وانسجامها على نحو نستبعد معه العشوائية.

ويرى وايتهيد: (أن الأهمية الرئيسة للترابط في الميتافيزيقيا تثضمن خاصية رئيسة لها تتمثل في تعقب النزعة العقلية إلى آخر مدى وما يترتب على ذلك من وجود ترابطات داخلية رئيسـة بين الأشياء، وأن العالم بما يحويه من عناصر للنظام والفوضى يشارك في تذعيم هذا الاتجاه)(15). وهنا

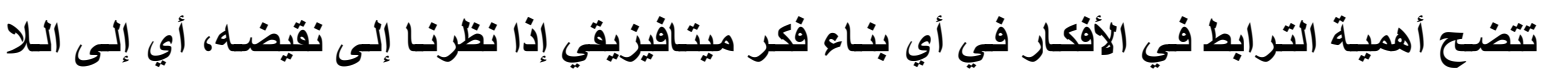

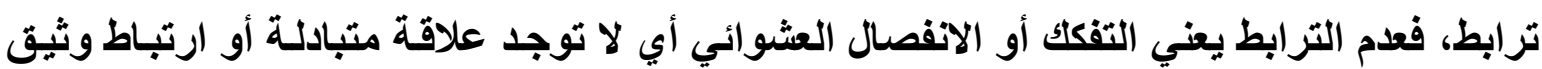
داخلي. ويرى وايتهيد ان الحقيقة عمليـة صيرورة مستمرة أو سيل من الأفكار لا ينقطع، يمكن اليطن تحليله إلى وحدات أساسية ذرية هي الحوادث وهذه الصيرورة هي محاولة فلسفية للاستفادة من

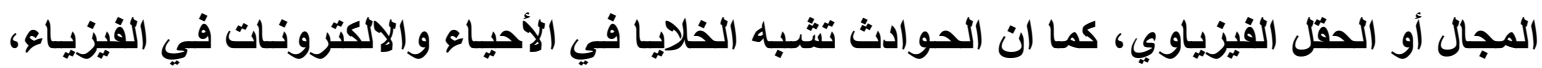
والحادثة نقطة زماتية ذات أبعاد أربعة يكون الزمان البعد الرابع فيها، وهي اقرب إلى الطاقة منها

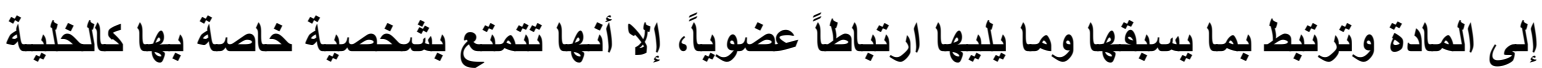
والإكترون وتعبر كل حادثة جديدة عن خلق أو إبداع. 
ل

ويعتقد وايتهيد أن الفلسفة والعلم (يرتمان بفهم الوقائع الفردية كأمثلة للمبادئ العامـة، يمكن

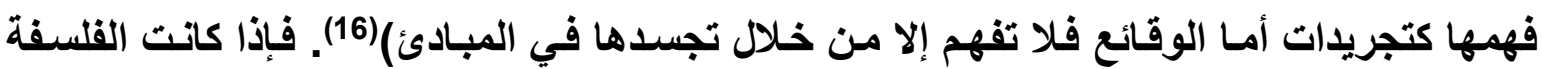
تبحث في التعميمات المميزة للواقع الكامل للحقيقة التي تصبح الحقيقة من دونه مجرد تجريـد، فـان العلم هو الأي يصنع التجريا وهو الأي يقدم الحقيقة لها.

3. تعد قضية ("المـنهج"، مسـألة أساسية في دراسـة المشكلات الميتافيزيقيـة وقد ظهرت هذه القضية بوضوح في موقف وايتهيد من المسألة. عـالج وايتهيد فلسفته الميتافيزيقية بمنهج علمي هو منهج التعميم الوصفي)(17)، وهذا المنهج لا يختلف كثيراً عن المنهج الاستقرائي، وأحياناً يسمى بـالمنهج الاستدلالي الاستقرائي، ويمسا ان وايتهيد فيلسوف تجريبي عقلي فان (تجريبيـة وايتهيد الجذرية تتجلى في تأكيده أن الانتقال من الخاص إلى العام أو من الخبرة الحسية إلى الحكم العقلي المستدل منها مباشرة يتم مباشرة بدون وساطة من مبادئ أو مفاهيم عقلية تكون غير مشتقة من من الجن

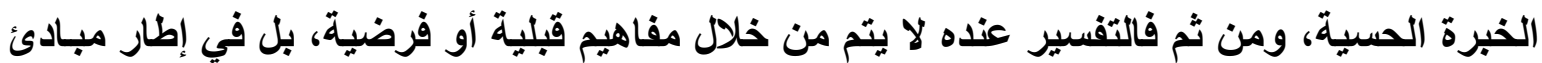
مبثوثة في الطبيعة، تكتثف خـلال الحدس أو خلال إدراكنا الحسي لها، وهذا يستفاد من قولـه أن الغاية مـن القلسفة الطبيعية، وصف الطبيعة القابلة للمعرفة الحسية بحدود مـا هو قابل للمعرفة

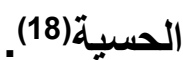

ويرى وايتهيد ان المنهج القلسفي ينطوي بالضرورة على التعميم، ويتضمن هذا التعميم عملية انتقال من الجزئي العيني إلى الكلي، وهو يقوم على الوصف أكثر ممـا يقوم على الاستتباط

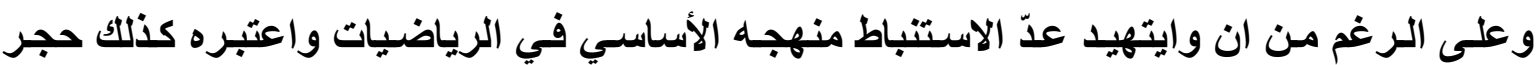
الزاوية في مجال البحث القلسفي، وبذلك يطبق منهج (منهج التعميم الوصفي) الذي يتخذ شكلا وصفيا للعملية الديناميكية وعنده انه أولى من ان يتولى وصف البه البنية الاستاتيكية، ويضع وايتهيد

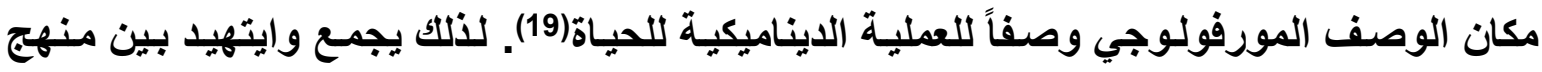
التعميم الوصفي وبين المنهج العلمي المعاصر من دراسة الميتافيزيقيا. لذلكك يرى أن أهم مـا يميز نظام وايتهيد الميتافيزيفي انه يحاول الاستعانة بوضوح بكل ما توصل إليه العلم الحديث في مختلف اختصاصاته وانه يحاول أن يربط وينسق بين حصيلة المعرفة الإنسـانية المعاصرة أي يجمـع بين

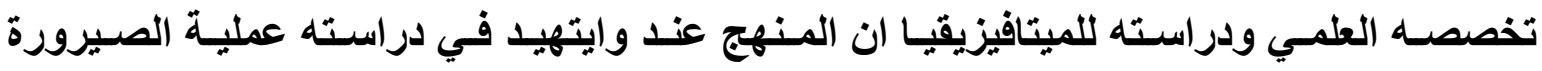
الطبيعية والايمومسة يقوم على جانبين: تجريبي وعقلانسي، لذلك حاول الانطلاق في الواقع لبنـاء

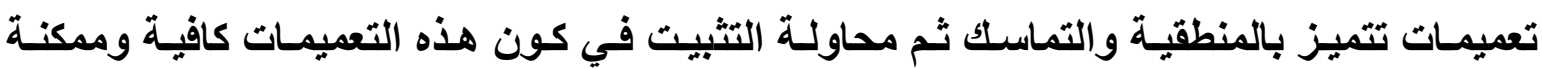
التطبيق على الواقع(20).

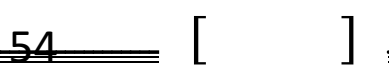


ل

ان مكونـات التجربـة لا يمكن ان تتبين أو تتضـح إلا بعمليـة صسعة مـن الاستـلال العقلي،

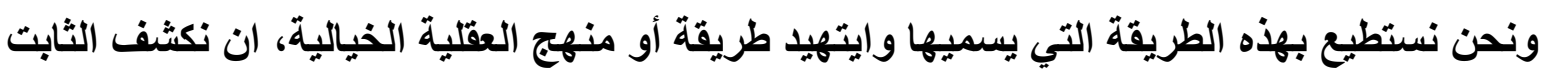

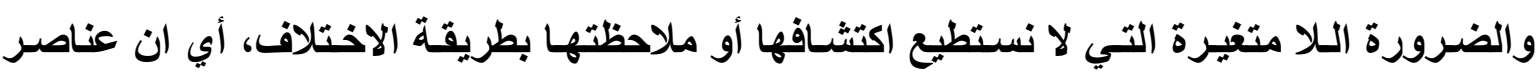

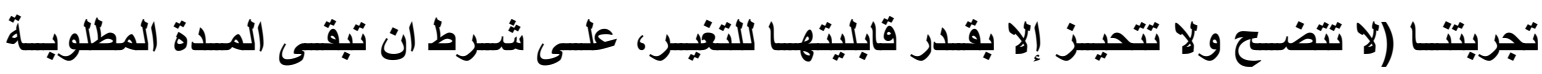
للأهمية)(21) ومن هذا الجانب الأيستمولوجي في دراسـة الميتافيزيقبا يقول وايتهيد: (ان طريقة العقلنة الخيالية تتجح فيما فشلت فيه طريقة الاختلاف، فهي تلاحظ الثابت الحاضر دائما الذي فثلت

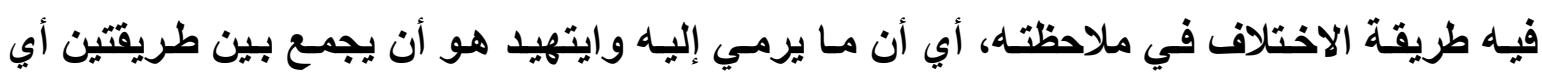

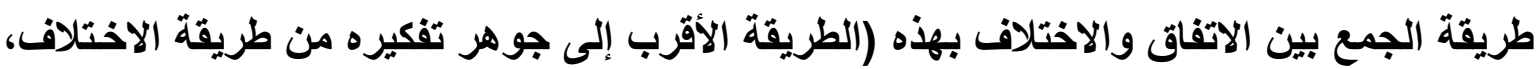
لان ما يتغير بوضوح يكون حاضراً لم يغيب أو يكون غائباً ثم يصبح حاضراً)(22.

أن وايتهيد في ميتافيزيقياه يهتم بتلك الطرق اهتماماً بالغاً لاسبما في البحث عن الخصسائص العامة للكائنات الفعلية ومحاولة اكتشافها بواسطة الخبرة، لذلك يقول وايتهيد من ذلك: (ان مـا هو

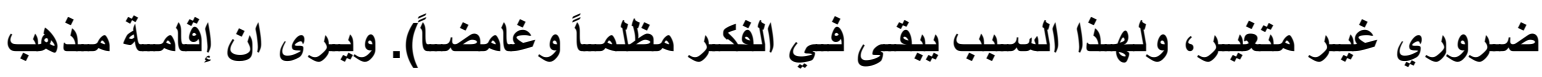
ميتافيزيفي أو بناءه يجب أن يتم بالمنهج الذي يجب إتباعه هو (التعميم التخيلي)، وهناك شرطان: فالأول هو البحث الدائب عن أمرين عقليين هما الاتساق، والكمال المنطقي(23). أما الثرط الثراني الثاني في الميتافيزيقيا فهو (السير بمنهج التعميم كي يتحقق ويطبق. واختبار نجاحه هو التطبيق في مجالات تجاوز المجال المباشر الذي نشأ منه، أو بعبارة أخرى يجب ان يحقق روئية جمالية)(24).

4. موقف وايتهيد من مشكلة الابستمولوجية والصيرورة الطبيعية:

لابد لنا من باية المسألة أن نعرف مسبقاً موقف وايتهيذ من قضية الابستمولوجية المعرفية

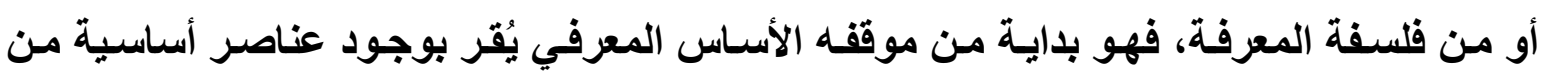
التجربة، وأخرى عقلاتية من العقل فالتجربـة والعقل ملتحمـان معاً في إطسار وحدة عضوية فوفية أصلية

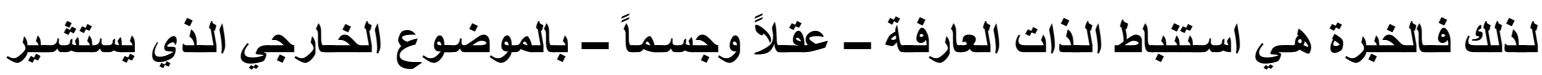
اهتمامه، ولولا ضرورة التحليل من اجل الفهم ما قلنا بوجود داخل أو خارج، فالإنسان والطبيعة هما شيء واحد تجمعهما الواقعة الطبيعية الشاملة(25). ويرى وايتهيد في أصول المعرفة الإنسـانية أن (الحياة العضوية تجمع بين العقل والجسم في وحدة واحدة، ثم تعود فتجمعهمـا بالعالم المحيط بها،

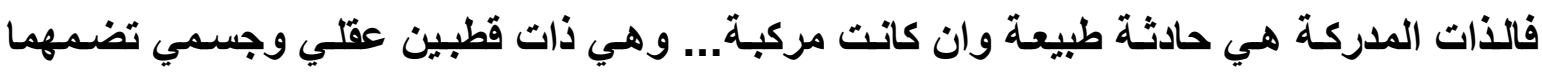

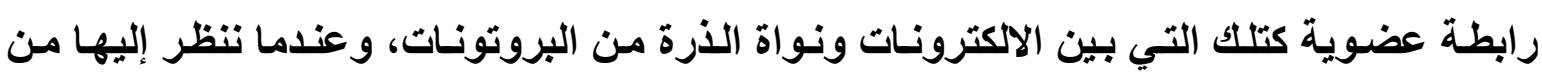

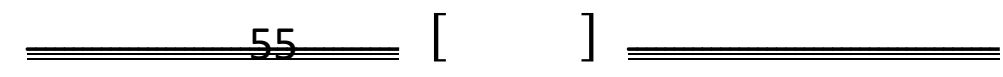


ل

الخـارج، نجد ارتباطهـا بـالحوادث الأخرى التي تكون البيئة وأي محاولـة ترى إلى تقتيـة الوحدة الداخلية أو تثنية الوحدة الخارجية هي ضرب من التجريد الضار بالقلسفة العلمية(26.

وعلى الرغم من أن نظرية وايتهيذ المعرفية وفلسفته من الميتافيزيقيا تعتمدان على أسس

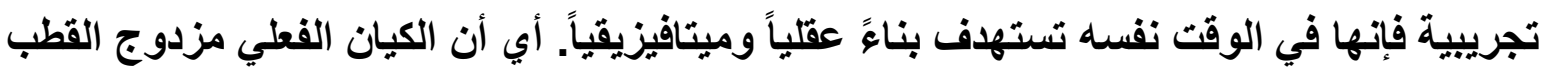
أي أنه يحتوي على قطبين هما القطب الفيزيقي والثاني القطب العقلي أي أننا نستطيع أن ننظر من من

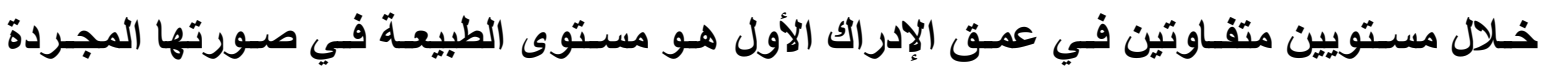

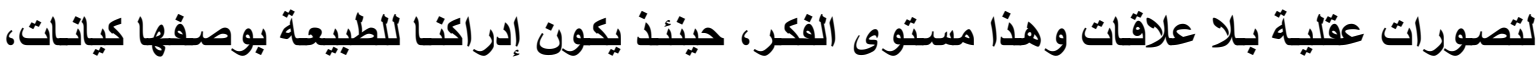
والثاني هو في صورتها العضوية بوصفها مركبة من حوادث وموضوعات ذات علاقات بينهمـا هذا هو مستوى الوعي الحسي ويكون إدراكنـا بهـا بوصفها عوامل Factors والكيان الذي هو هو من هن

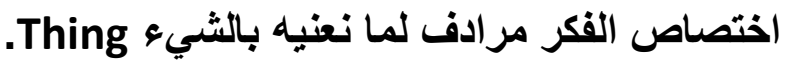

إذاً هناك قطبان في كل كيان فعلي، قطب عقلي، وقطب فيزيقي، وهما يرتبطان تمـام الارتباط وفي هذا الصدد يقول وايتهيد: (إن القطب العقلي ينبع كمتمثل تصوري لعمليات القطب القيزيقي، والقطبان لا يفصلان من أصلها، فالقطب العقلي يبأ مـع التسجيل التصوري للقطب الفيزيقي)(27). وفي هذه النظرة الابستمولوجية هناك تناست مع نظرته الميتافيزيقية أو مع مبأ الانطولوجي، ذلك ان هذا المبلأ يقتضي ان تكون المشاعر التصوريـة الأولية مشتقة من المشـاعر الفيزيقية الأوليـة،

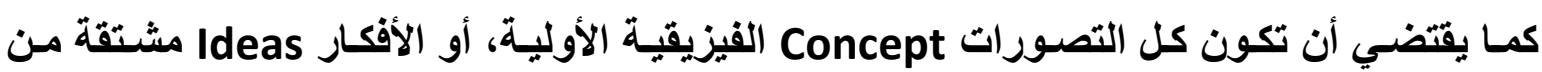
المحل الأول من الخبرة الفيزيقية المباشرة بالفعاليات الأخرى، وحسب ملاحظة وايتهيد وعلى حد تعبيره (فان مقولة التوليا التصوري، تؤيد المبدأ القديم القائل بـان الخبرة الحسية نتاج العمليات العقليـة)(28) فمهمـة القلسفة الأولى التوحيد الكامـل بين مكونـات التفكير العقلي، أو بمعنى أخر التسيق وإعادة التحديد، والإحكام الواضـح، وضبط الاتجاهـات المختلفة للمعرفة الإنسـانية كـالعلوم والجمال والاخـلاق والدين وهي تثكامل جميعها لتشكل فلسفة المعرفة، فهي أشبها بـأدوات الفكر العقلانـي التي تتناسق فيمـا بينهـا لتكوين مبدأ الوجود. ويتضمن مبدأ الوجود مـا يمكن تسـيته (بالإمكانية المعرفية)(29)، وهذا المبدأ يعني ان كل العمليات العقلية المركبة تعتمد كمـا أسلقنا على مئى

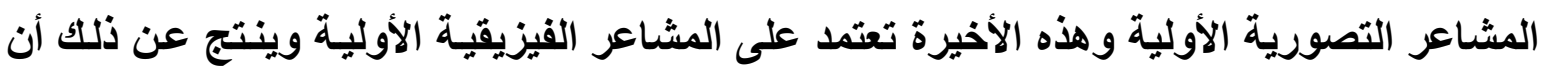
الفكر عند وايتهيذ يعتمد ويرتكز على الخبرة الحسية إلا أن وايتهيذ يرى أن علينا أن نتصور الخبرة الحسية في ضوء المشاعر الفيزيقية الأولية البسيطة المنتظمة في القطب الفيزيقي، التي يبدأ منها

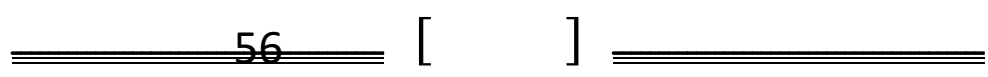


ل

ما أسماه بالتسجيل الصوري، يقول وايتهيد في بداية هذا الموضوع: (ان التسجيل الصوري يؤلف المادة الوحيدة للخبرة في رأي مدرسة الحسيين وهذا يعني ان هذه المدرسة أغقلت تمامـاً المشـاعر هور

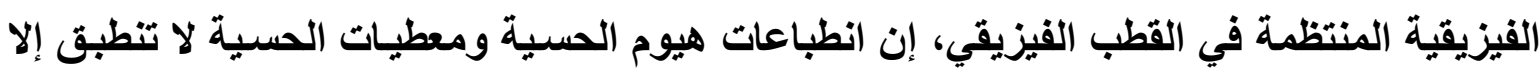
على التشجيل الصوري)(30).

هذه العمليـة التجريديـة تعد ذات أهميـة كبيرة حيث أنهـا تختص بعلاقة التفسير العقلي أو

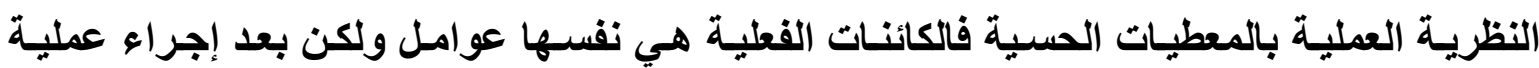
تجريد بعدي عليها وهذا يؤكد اتصسال العقل بالطبيعة وعدم اكتفاء أي منهم بذاته، ولكن المهم أن أن

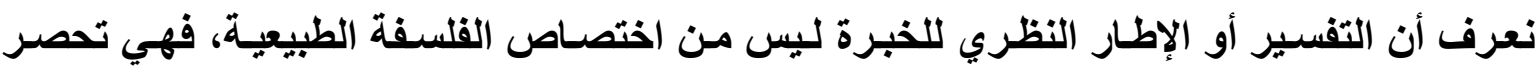
نفسها فيمـا هو مدرك فقط ولا تقحم نفسـها في علاقة المعرفة)(31). والفرق بين الإدراك الحسي في الكي

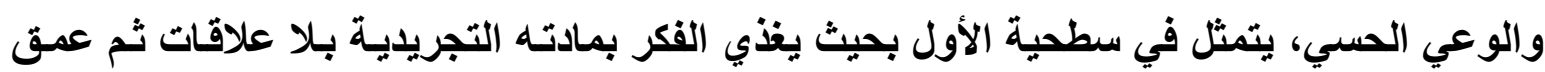

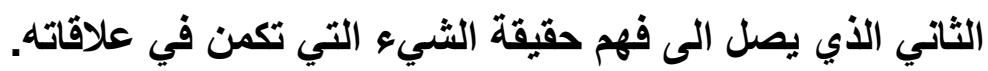

وفي ضوء التصور الحي للخبرة، يرفض وايتهيد ان نعد الطبيعة البشرية ماهية وجودية فهذا المفهوم إن جاز أن ينطبق على إنسان مـا فهو أجدر بـالجنين في بطن أمسه, فالإنسان هو مجموع

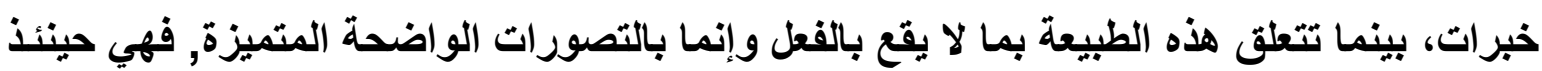
تثبت شيئا واحدا هو إنسانيتنا كما هي, فلا يكفي لكي يوجد الإنسان ان يفكر بل الفكر في كل شيء له وجود حقيقي. لذلك قرر وايتهيد (أن جوهر اللاعقلانية متضمن في التلا ترابط، وأنتا إذا قبلنا المذهب اللا عقلي، فأنتا نقبل في الوقت نفسه قبولاً صريحاً أو مضموناً للفصل التعسفي)(32. أي أن المذهب اللاعقلاني يتضمن إنكار العقل ومن ثم إنكار المبادئ العامة سواء أكاتت مطلقة العمومية أم أقل درجة في العمومية مما يهتم العلم؟... وبذلك وايتهيد يهاجم المذهب الوصفي تجاه موقفه من الميتافيزيقيا وهدفه لكل فكر ميتافيزيقي، وفي مواضع متفرقة من مؤلفاته هاجم هذا الموقف ويرى

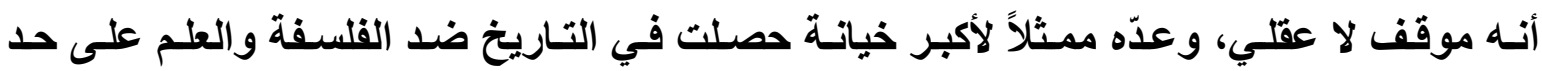
سواء)(33) مون.

أن نشأة الفيلسوف الميتافيزيقي، وهو يقيم البناء الفعل بنتائج مستمرة من مبادئ عقله هو،

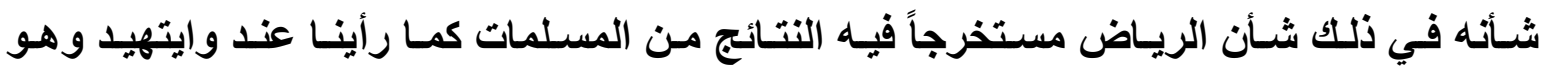
الفيلسوف الرياضي فقد اعتبر النسث الميتافيزيقي قابل للتطبيق بالنسبة لمختلف الوقائع أو هو على ماتى

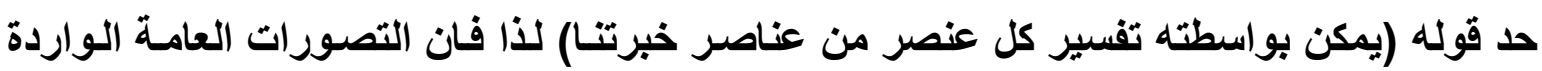


ل

فيه، هي في حقيقتها اقرب ما تكون إلى المتغيرات التي نجدها في الرياضـة والمنطق والتي يكون

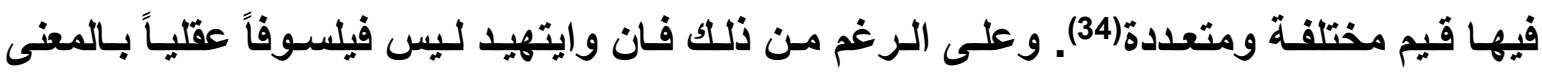
التقليدي كما هو متعارف عليه مثلاً عندما نصف (ديكارت) بأنه فيلسوف عقلي، إلا أن وايتهيد يعد اختبار الواقع وممارسته مباشرة أمرا لا يضـاهيه شيء ، وكذلك هو يبحث عن علة الأشياء من خلال طبيعة الموجودات الواقعية ذاتها.

5. التفسير الميتافيزيقي للصيرورة الطبيعة: في مشكلة المكان و الزمان في القلسفة العضوية عند وايتهيد

يحرص العلم على ان تكون لايه معطيات دقيقة ومنظمة عن العالم ، وذلك من اجل صياغة المفاهيم والفروض صياغة رياضية ولاسيما وان العالم في نظر وايتهيد عالم عضوي في المقام الأول، أي يستحيل تصنيف مكوناته واستبعاد بعضها في ظروف من اجل التحكم في الدقة، فالعالم في رأي وايتهيد لا يتكون من أشياء بل من حوادث، أي يتألف ممـا يتم حددته فكل امتداد زمـاني للحادثة ، وكل خطوة من خطوات التجربة وكل ذرة من ذرات الوجود يحتل مناسبة زمانية معينة. ولهذا ألصقت الحوادث بخاصية جديدة هي نتاج اللقاء أو التقاء الزمسان بالمكان. هذه التخصصية

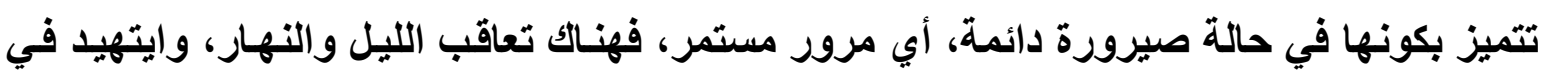

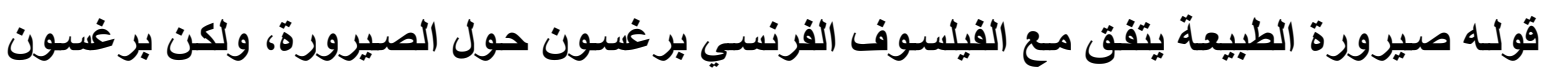

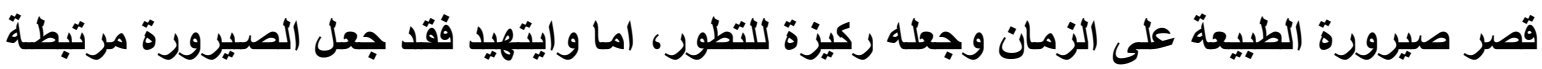

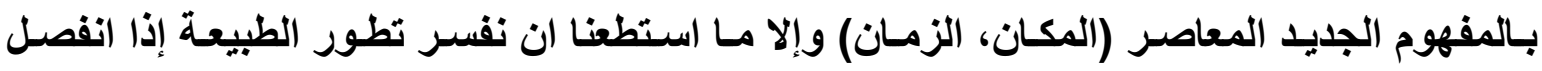
الزمان عنها(35)، غير ان البعض يمكن ان يعترض على صيرورة الطبيعة بالقول انه توجد أنماط من

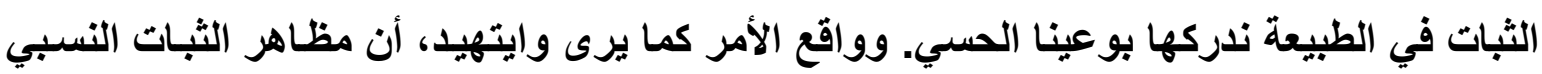

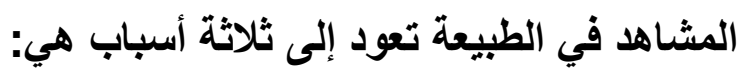
أ. البطء الشديا الذي يتم به التغير. ب. قصور الإدراك الحسي السطحي عن ادارك حركة الحوادث. ج. أن العلاقات بين الحوادث والموضوعات تكسب الحوادث صفات ذات ديمومة نسبية.

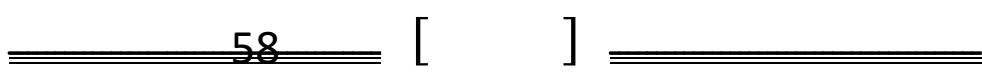


ل

ثمة حقائق عند وايتهيد في مرور الحوادث فمرور الحوادث ليس مروراً دائرياً، أنما مستقيم

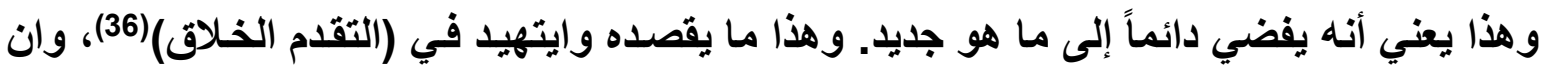
مرد الحوادث يعني انتقالها من مرحلة الفعل الحاصر إلى مرحلة الممكن، وعلاقة الامتداد تدعم هذا

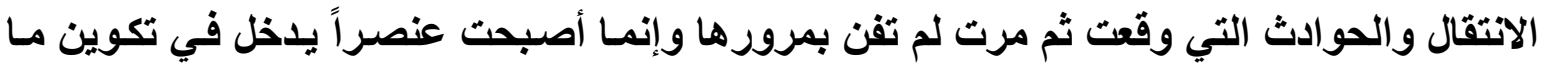
هو حادثة وما سيحدث في المستقبل وهذا معناه أن الماضي غير قابل للإلغاء وإنما يشارك في صنع الحاضر والمستقبل(37)، لألك وجب علينا أن نسلم بان كل الأي نلاحظه حوادث، وما دامت الحوادث موجودة، فان الزمان موجود، وإذا انعدمت الحوادث من الوجود النقي الزمان ولم يعد له وجود (38). كما لا يمكن فهم الزمان في ميتافيزيقيا وايتهيذ بدون فهم مسألة المكان، ولا فهم المكان من دون الزمان، لذلك يقول الكاتب الانكليزي مييز: (فلا يمكن أن يوجد مكان بلا زمان، ولا يوجد زمـان

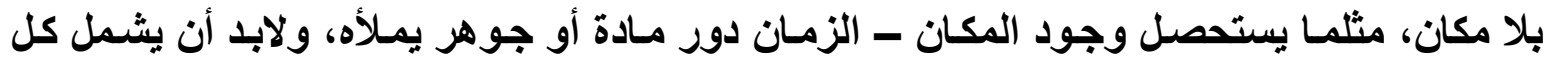

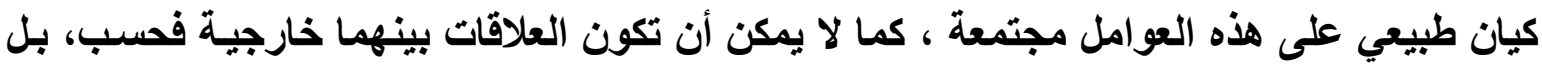

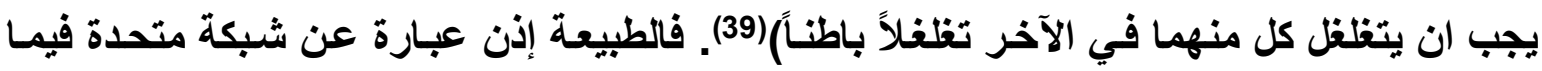
بينها، تتداخل أجزاؤها بعضها من بعض، والحوادث ليست زمانية فقط كما يفهما الآخرون، بل أنها ديمومة زماتية مكانية في الوقت نفسه.

عرّف وايتهيذ مفهوم (التدفق) أو المرور: بأنه هو تدفق الزمسان في الطبيعة بمـا يعبر عن

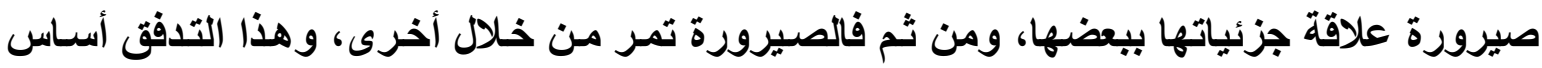

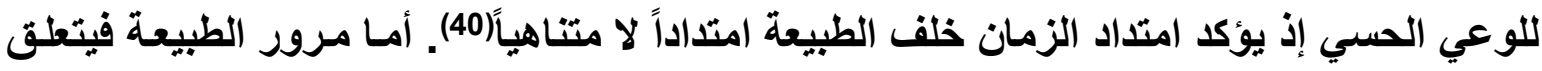

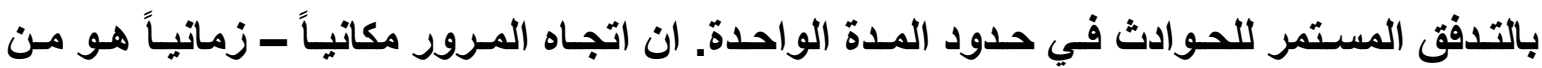

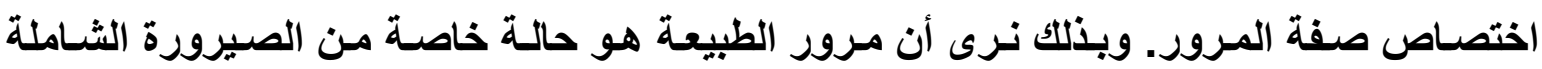

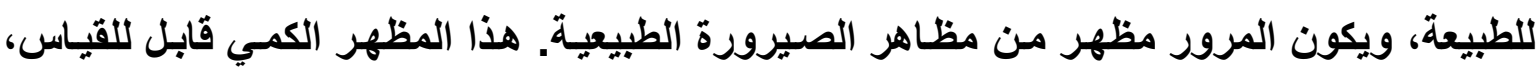
وهو ما يهتم به العلم، أذن فالمدة الواحدة لا تجسد المرور، ويتم ذلك من خلال النسث الزمني الذي هي هئي يتضمن العديا من الحوادث، والحادثة تمثيل امتداداً متساويا في كل من الزمان والمكان، هذا الامتداد

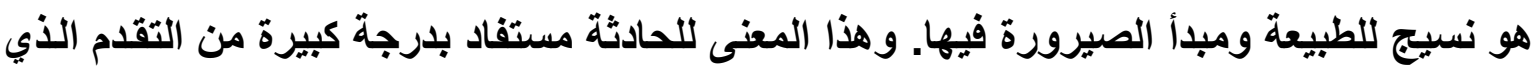
أحرزه علم الفيزياء في القرن العشرين فلم يعد هناك مكان ثم زمان، فقد حلت الحادثة محل الجوهر القديم(41)، وأصبح ارتباط الزمان بالمكان هو أساس حركية الحوادث والطبيعة ككل هذه الحركية هي

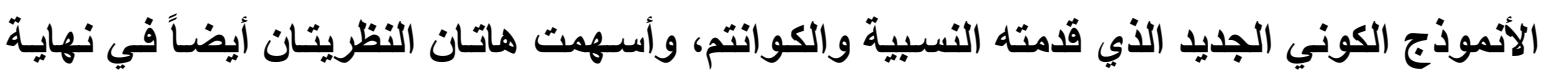

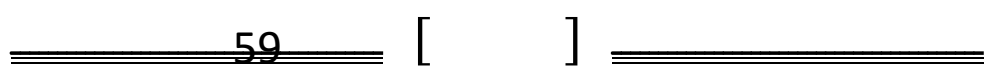


ل $\int_{2010}$

فكرة المادة كحقيقة قصوى لتحل محلها الطاقة وبذلك يقترب(42) مفهوم الطاقة من مفهوم الحوادث، فالحوادث وقوع ذو انتشار مكاني زماني. فكرة (منهج التجريد الامتدادي) وأهميتها في ميتافيزيقيا وايتهيد:

منهج التجريــ الامتدادي(43) كمـا قدمسه وايتهيد (أسـلوب تحليـل كيفيـة استتاد الطبيعـة السى التجربة بوصفها تجربة لطبيعة الأثياء وليست تجربة للنقاط أو المسـاحات، فهو وان كان رياضياً إلا أنه يستند إلى الخبرة الحسية في الوصول إلى النتائج مما يؤدي الى تحديد العلاقة بين التصور العقلّي وبين الواقِع التجريبي، وعليه فوايتهيد أراد ان يثبت انـه بالإمكان تحليل مكونـات الخبـر

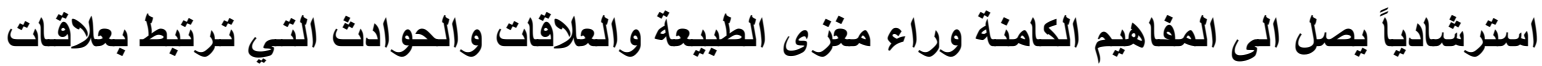
فيما بينها، وفي هذا الصدد يقول الدكتور محمد مهران (ان منهج التجريد الامتدادي هو طريقة

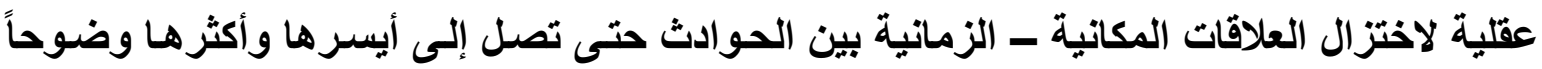
ودقة، ومن ثم فهو الطريقة التي بها تتم ترجمة غموض واختلاط معطيات الخبرة الى وضوح ودقة العقل، فإذا صح القول ان المفاهيم التحليلية بثكل عام هي أساليب توصلنا إلى معرفة أكثر وضوحاً

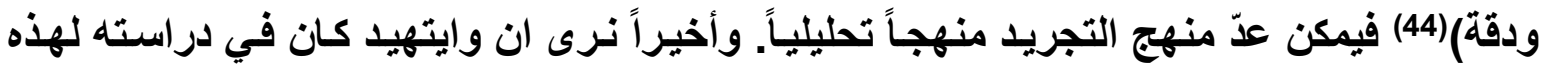

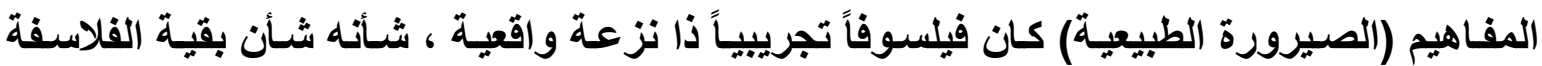
الانكليز ، يعتقد أولاً في وجود العالم الخـارجي وجوداً مستقلاً منفصلاً عن وجود الذات الإنسـانية وفية

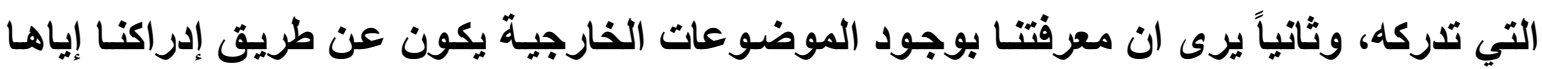
بالتجربة الحسية، إلا أن وايتهيد يتجاوز تلكا التجربة إلى مستوى العقل الذي كان يؤمن بـه إيمانـا وثيقاً، وأعطى للعقل دوراً ايجابياً مهماً.

هوامش البحث:

(1) Whitehead: A , N , Process and Realty , New York , Macmillan company , 1929, P.103.

(2) Whit head: A, N, Process and Realty, New York, Macmillan company, 1929, P. 103.

(3) Whit head: A, N, Science and modern world, New York, 1925, P.178, 179.

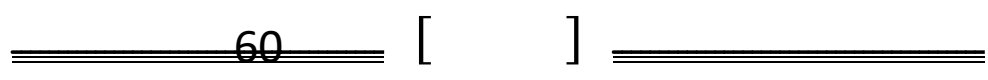


ل $\underbrace{}_{2010}$

(4) Whitehead : Process , P.215.

(5) خليل، د. ياسبن ، مقدمة في الفلسفة المعاصرة، منشورات الجامعة الليبية، كلية الاداب، 1970، ص203.

(6) محمد، د. علـي عبد المعطي، الفرد نـورث وايتهيد فلسفته وميتافيزيقيـاه، سلسـلة دراسـات الفلسفة الحديثة

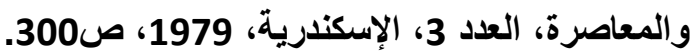

(7) White head : Process and Reality , P.27.

(8) White Head : Adventures of ideas, New York, Macmillan, Press, 1933 , P.200.

(9) White Head : Process , P.3.

(10) White head : Religbn the Making, P.72.

$$
\begin{aligned}
& \text { (11) محمد ، د. علي عبد المعطي : الفرد نورث وايتهيد فلسفة وميتافيزيقياه، ص168. } \\
& \text { (12) رجب ، د. محمود : الميتافيزيقيا عند الفلاسفة المعاصرين ، ص305. } \\
& \text { (13) محمود ، د. علي عبد المعطي: وايتهيد وفلسفته وميتافيزيقياه، ص171. }
\end{aligned}
$$

(14) White head : Process and Reality , P.7.

$$
\text { 15 محمد ، د. علي عبد المعطي : وايتهيد فلسفته وميتافيزيقياه : ص175. }
$$

(16) White head : Adventures of Ideas, New Yourk, Macmilian company , 1933 , P.179.

(17) بدوي، د. عبد الرحمن: الموسوعة الفلسفية، ج2 ، المؤسسة العربية للاراسات والتوزيع ، القاهرة، 1986 ،

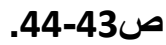

$$
\begin{aligned}
& \text { (18) ابراهيم ، د. زكريا: دراسات في القلسفة المعاصرة، مكتبة مصر، القاهرة ، } 1968 \text { ، ص176. } \\
& \text { (19) بذوي ، عبلد الرحمن : الموسوعة الفلسفية ، ص43-44. } \\
& \text { (20) محمد ، د. علي عبد المعطي : وايتهيد فلسفته وميتافيزيقياه ، ص185-186. } \\
& \text { (21) رجب ، محمود : الميتافيزيقيا عند الفلاسفة المعاصرين ، ص314. } \\
& \text { (22) محمد ، د. علي عبد المعطي : وايتهيد فلسفته ومتيافيزيقياه ، ص189. } \\
& 61=[\quad] \equiv
\end{aligned}
$$


ل

(23) رجب ، د. محمود : الميتافيزيقيا عن الفلاسفة المعاصرين ، ص317.

(24) المصدر نفسه ، ص317.

(25) إسلام، د. عزمي: اتجاهات في الفلسفة المعاصرة، الناشر وكالة المطبوعات، الكويت، 1980، ص218.

(26). White head : Process and Reality, P.127-129.

(27). Whit head : Process and Reality , P.18.

(28). Ibid , P.351.

(29). Ibid , P.351.

(30).White head : Process and Reality, P.127-129.

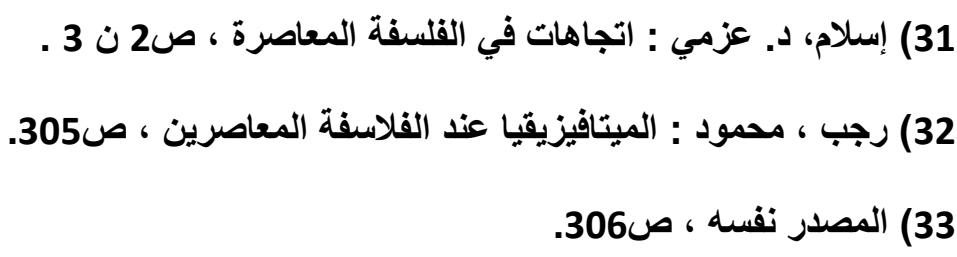

(34) Whitehead: Modes of Thought, New York, Macmillan Press, 1938, P. 202-203.

(35). Whit head: The Concept of Nature, P.54., Tarner Lectures m 1919, Cambridge Unig Press, 1920.

$$
\begin{aligned}
& \text { (36) إسلام، د. عزمي : اتجاهات في الفلسفة المعاصرة ، ص213-214. } \\
& \text { (37) وايتهيل : مغامرات الأفكار ، ص310-309. } \\
& \text { (38) المصدر نفسه ، ص313-314. } \\
& \text { (39) ميتز ، رودلف: القلسفة الانكليزية في مائة عام ، ترجمة فؤاد زكريا ، مراجعة د. زكي نجيب محمود ، دار }
\end{aligned}
$$

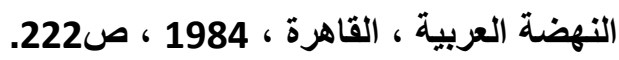

(40) Whit head : The Concept of nature , P.55, 56.

$$
\text { (41) إسلام ، عزمي : اتجاهات في القلسفة المعاصرة ، ص211. }
$$

(42) خليل ، ياسين : مقدمة في الفلسفة المعاصرة ، ص240-241 .

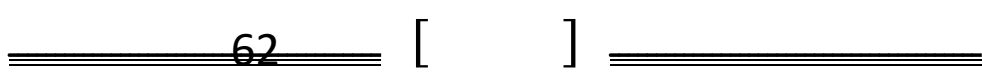


ل $\int_{2010}$

(43). Whit head : The Concept of nature, P.74.

(44) دشوان ، د. محمد مهران : فلسفة برتراند رسل ، دار المعارف ، مصر، 1979 ، ص335-336.

قائمة المصادر:

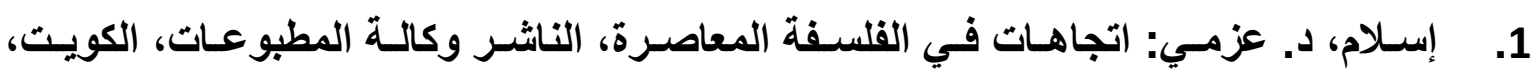

2. ابراهيم، د. زكريا: دراسات في القلسفة المعاصرة، مكتبة مصر، القاهرة، 1968. 3. بدوي، د. عبد الرحمن: الموسوعة الفلسفية، ج2، المؤسسـة العربيـة للاراسـات والتوزيع،

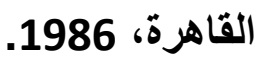

4. خليل، د. ياسين: مقدمـة في الفلسفة المعاصرة، منشـورات الجامعة الليبية، كلية الآداب، طرابلس،

5. دشوان، د. محمد مهران: فلسفة برتراند رسل، دار المعارف بمصر، مصر، 1979. 6. رجب، محمود: الميتافيزيقا عند الفلاسفة المعاصرين، منثأة المعارف، الاسكندرية، 1970. 7. محمد، د. علي عبد المعطي: الفرد نورث وايتهيد فلسفته وميتافيزيقياه، سلسلة دراسـات الفلسفة الحديثة والمعاصرة، العدد 3 ، الاسكندرية، 1979. 8. ميتز، رودلف: الفلسفة الانكليزية في مائة عام، ترجمة فؤاد زكريا، مراجعة د. زكي نجيب محمود، دار النهضة العربية، القاهرة، 1984. 9. وايتهيد، الفرد نورث: مغامرات الافكار، ترجمة انيس زكي، مراجعة محمود الامين، مطبعة

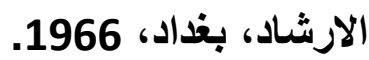

10. White head: A. N. adventures of ideas, New York, Macmillan, company, 1933.

11. Whit head: A, N, Process and Realty, New York, Macmillan, 1929. 
ل $\int_{2010}$

12. Whit head: A, N, The concept of nature, Cambridge, Press, 1920.

13. Whit head: A, N, Science and modern world, New York, 1925.

14. Whit head: A. N. Religion the making, Cambridge Univ., Press, 1926.

15. White head : A. N. Modes of thought $m$, New York, Macmillan, Press , 1938. 